\title{
Empirical Research on Primary School Mathematics Teachers' Understanding of the Situations of Students' Learning in Extra-Curricular Time
}

\author{
Zezhong Yang, Wangchen Kan, Zhaohua Qu, Dandan Sun, Zemin You \\ The School of Mathematical Sciences, Shandong Normal University, Jinan, China \\ Email:zhongzee@163.com
}

Received 2 Januar 2015; accepted 25 January 2016; published 29 January 2016

Copyright (C) 2016 by authors and Scientific Research Publishing Inc.

This work is licensed under the Creative Commons Attribution International License (CC BY). http://creativecommons.org/licenses/by/4.0/

(c) (i) Open Access

\begin{abstract}
This research focused on the current state of primary school mathematics teachers' understanding of students' learning situations, and adopted open-ended structure questionnaire. A total of 35 primary school mathematics teachers from five cities of Shandong Province participated in this survey. This research adopted the face-to-face way to collect information. The results indicated: 1) The number of students which most primary school mathematics teachers looked for to understand learning situations was generally not more than 10 people $(85.7 \%)$; 2 ) The type of students which most primary school mathematics teachers looked for to understand learning situations was mainly backward students $(\mathbf{9 7 . 1 \% )}$; 3 ) The content that most primary school mathematics teachers understood from students was their mastery of knowledge (82.9\%); 4) The main way of understanding was direct inquiry $(83.7 \%)$. So the primary school mathematics teachers' work of understanding students' learning situations was obviously too simple and incomplete, this perhaps was the fundamental reason that caused some present primary school mathematics teaching difficulties.
\end{abstract}

\section{Keywords}

Mathematics Teaching, Understanding Learning Situations, Primary School, Extra-Curricular Time

\section{Introduction}

Modern primary school mathematics education paid special attention on student-oriented teaching [1]-[3]. To

How to cite this paper: Yang, Z.Z., Kan, W.C., Qu, Z.H., Sun, D.D. and You, Z.M. (2016) Empirical Research on Primary School Mathematics Teachers' Understanding the Situations of Students' Learning in Extra-Curricular Time. Open Journal of Social Sciences, 4, 165-169. http://dx.doi.org/10.4236/jss.2016.41020 
implement student-oriented teaching, understanding students’ learning situations must be go first, especially in primary school [4]-[6]. Hence, there were many researches on how to understand students' learning situations, such as the work of Gao zilin, Gao sunzhu, Zhou yulan and Chen qiong [7]-[10]. Gao zilin thought the reasonable process should be putting forward hypothesis, investigating in depth and analyzing comprehensively. Gao sunzhu thought the best way was to start from the life knowledge of students, and then summarize it. Zhu yulan argued the effectively way was to test all students' basic knowledge before class. Chen qiong considered that the students' basic experience, cognitive law, cognitive style and interest must be taken into account when teachers understood students' learning situations. However, what was the real state about understanding students' mathematics learning situations in primary school? According to our observation in several primary schools, it didn't seem ideal. Because there were still many teaching and learning difficulties in the process of current mathematics teaching [11]. How did the current primary school mathematics teachers understand students' mathematics learning situations? Did some deficiencies exist in the situations? What needed to be further increased or improved? Reviewing the current researches about this problem, there were no clear answers. So we chose some primary school mathematics teachers and conducted a survey.

\section{Methodology}

\subsection{Instrument}

To know the state of primary school mathematics teachers' understanding students' learning situations in extra-curricular time completely and in depth, we adopted an open-ended structure questionnaire on the base of relevant literature and questionnaires. Our questionnaire contained five questions and mainly was related to the various ways of current primary school mathematics teachers to understand students' learning situation in extra-curricular time.

\subsection{Participants}

We recruited randomly 35 primary school mathematics teachers as respondents from Jinan city, Qingdao city, Yantai city, Zibo city and Dongying city. These 35 teachers consisted of 21 female teachers and 14 male teachers, in which 13 younger teachers aged in 35 years old, 14 middle-aged teachers which aged between 35 and 50 , and 8 older teachers aged over 50 .

\subsection{Data Collection}

To collect data, we interviewed all 35 primary school mathematics teachers we recruited face to face, recorded their responses at first, and organized them into text after that.

\subsection{Data Analysis}

We encoded the recording materials with qualitative analysis software nvivo10 at first, and then analyzed the codes in table and calculated the percentages of each code. All answers were obtained from these percentages.

\section{Results}

\subsection{The Number of Students}

Regarding the number of students for understanding students' learning situation, 51.4\% of teachers usually looked for 2 to 5 students, 34.3\% of teachers usually looked for 6 to 10 students, and only about 10\% of teachers looked for more than 10 students before class. While after class, $48.6 \%$ of teachers often looked for 6 to 10 students, $11.4 \%$ of teachers usually looked for 2 to 5 students, only about $10 \%$ of teachers also looked for more than 10 students. The details were as shown in Table 1.

\subsection{The Types of Students}

Almost all Chinese mathematics teachers got used to dividing students into outstanding students, middle students and backward students. The backward students seemed to be particularly concerned in the daily time, since there were about $97.1 \%$ of teachers usually looked for backward students to understand students’ learning 
Table 1. The number of students for understanding learning situations.

\begin{tabular}{ccc}
\hline Number & Before class (percentage of teachers) & After class(percentage of teachers) \\
\hline 2 - 5 students & 51.4 & 11.4 \\
6 - 10 students & 34.3 & 48.6 \\
10 - 20 students & 5.7 & 8.6 \\
$\begin{array}{l}\text { More than } 20 \\
\text { students }\end{array}$ & 5.7 & 5.7 \\
\hline
\end{tabular}

situations before class. And after class, there were still $61.4 \%$ of teachers usually looked for them to understand learning situations. The outstanding students seemed not to be concerned, especially after class. The details about types of students were as shown in Table 2.

\subsection{The Contents of Understanding}

The contents which current primary school mathematics teachers understood form students seemed many and multifaceted in extra-curricular time. They were shown as Table 3. From Table 3, we know $82.9 \%$ of teachers mainly understood students' mastery of knowledge before class, $80.43 \%$ of teachers usually understood students' mastery of knowledge after class. $31.4 \%$ of teachers used to understand the confusion of new knowledge before class. Only about $3 \%$ of teachers understood the emotions and learning method of students.

\subsection{The Ways and Specific Method of Understanding}

The ways that teachers adopted to understand learning situations could be divided into the direct and the indirect simply. Before class, $83.7 \%$ of teachers used to inquire students for understanding their learning situations directly. While after class, $38.3 \%$ of teachers used to understand students' learning situation with indirect way, that was through home works or exercise. What Table 4 showed were the ways and the specific method of understanding adopted by current primary school mathematics teachers. From Table 4, we know methods adopted by teachers after class was a little much than before class, and the number of teachers adopted each method after class was around $20 \%$.

\section{Discussion}

From the above we knew current primary school mathematics teachers had two obvious characteristics when they understood students' mathematics learning situations in extra circular time: 1) lacking of comprehensiveness. It can be seen from Table 1, the number of students that most teachers to understand in general were less than 10 people either before class or after class. Currently primary school class size in mainland china was generally about 50 kids and a mathematics teacher usually guided two classes. So the number of students which teachers understood accounted for only one tenth of the total. And from previous data we could know that the majority of teachers used to inquire the backward and middle students when they understood the students' learning situations currently, minority of teachers cared about the outstanding students, especially after lesson. And according to the recently statistics, the outstanding students who was good at mathematics in one class of primary school almost account for one third of the total in generally. Thus, the understanding of large number of mathematics teachers was incomplete at present. 2) Understanding ways was too simple. From the contents of understanding we could know, most of mathematics teachers to understand students "learning situations currently only understood the situation of mastery of knowledge and less on others, particularly on students" learning methods and interests. Indeed, from the results of survey, we found none of mathematics teachers cared about students' mathematics learning abilities and motivations. In addition, it can be seen from the foregoing data, currently the ways that most teachers understood students' learning situations were direct request, less teachers used other ways, especially before class. It was not undesirable to understand the student's learning situations by using direct ways, but obviously it could not make teachers to understand fully, accurately and in depth, and did not guarantee the teachers to obtain the real learning situations. 
Table 2. The details about types of students.

\begin{tabular}{ccc}
\hline Levels & Before class (percentage of teachers) & After class (percentage of teachers) \\
\hline Outstanding students & 34.3 & 8.6 \\
Middle students & 57.1 & 48.5 \\
Backward students & 97.1 & 61.4 \\
\hline
\end{tabular}

Table 3. The contents of understanding.

\begin{tabular}{cccc}
\hline Contents & Before class (percentage of teachers) & Contents & After class (percentage of teachers) \\
\hline $\begin{array}{c}\text { Mastery of knowledge } \\
\begin{array}{c}\text { Learning interests and } \\
\text { attitudes } \\
\text { confusion of new } \\
\text { knowledge }\end{array}\end{array}$ & 82.9 & Mastery of knowledge & 80.43 \\
Changes in psychology & 31.4 & Confusion & 17.1 \\
$\begin{array}{c}\text { Experience of knowledge } \\
\text { Link in important } \\
\text { knowledge }\end{array}$ & 5.7 & Seatwork & 12.3 \\
Family situation & 2.9 & Learning method & 5.7 \\
learning method & 11.4 & Elassroom learning & 2.9 \\
\hline
\end{tabular}

Table 4. The ways and specific method to understand learning situations.

\begin{tabular}{ccccc}
\hline & Ways & $\begin{array}{c}\text { Before class } \\
\text { (percentage of teachers) }\end{array}$ & Ways & $\begin{array}{c}\text { After class } \\
\text { (percentage of teachers) }\end{array}$ \\
\hline Direct & Inquiry & 83.7 & Inquiry & Test \\
& Simple Exercise & 8.6 & indirect & Homework or exercise \\
& Simple Quiz & 14.3 & Summarizes & Communication with \\
& Questionnaire & 5.7 & & parents \\
\hline
\end{tabular}

\section{Conclusions}

Although the teachers we chose were not many, only 35 indeed, and also the number of questions in our survey were not large, only four actually. However, our research didn't lose generality. The 35 primary school mathematics teachers all were coming from average primary schools and the questions we investigated were not only related to methodology and contents but also involved the aspects of personnel. As can be seen from above figures, currently it was not very comprehensive and deep for majority of primary school mathematic teachers to understand students' learning situations. The incomplete mainly reflected that the number of students that teachers looked for was not adequate, and mostly of them were backward students. Thus only about one-third students in class were understood by most teachers at present. The not deep mainly embodied in contents that the teachers understood and the methods that the teachers adopted. In contents, nowadays the majority of teachers to understand students' learning situations concentrated on the mastery of knowledge, hardly involved to other aspects, rare teachers understood students' method, readiness and abilities about mathematics learning. In methods, currently a large number of the teachers adopted face to face way to inquiry, other ways were usually ignored.

The incomplete, inadequate and not in depth understanding situations of the students' learning mathematics would certainly cause the phenomenon that the teaching of teachers was inconsistent with the learning of students, and would resulted in the student's learning difficulties, thereby reduced the guiding efficiency. Therefore, in order to prevent the occurrence of such a situation, we suggested that primary school mathematics teachers 
should think over comprehensively when they understood the students' learning situations. They should ensure that the participated students' understanding activities could not only represent all students, but also reach the appropriate proportion; Primary school mathematics teachers should actively learn the theoretical knowledge of understanding the learning situations, found out what really understanding learning situation was about, what content should be understood, what degrees of depth should be focused on etc. Primary school mathematics teachers should pay attention to scientificity and rationality of methods of understanding learning situations, to ensure that the methods can help them understand learning situations in-depth and comprehensively, and obtain authentic mathematics learning situations.

\section{References}

[1] Xu, J. (2001) Based on Development of Students-The Value Orientation of The End of 20 Century America, British and Japan Textbooks Reform. Foreign Primary \& Secondary Education, 5, 29-33.

[2] Shen, J.M. and Xie, L.M. (2002) Student-Centered: The Basic Concept of Modern Classroom Teaching Design. Educational Theory \& Practice, 8, 48-52.

[3] Yang, S.S. (1998) Building Concept of Modern Education Base on Students’ Develop. Foreign Primary \& Secondary Education, 6, 27-31.

[4] Deng, J.P. (2014) Student-Centered: Possibility and How to Implement. Education Research, 6, 67-72.

[5] Wu, Q.H. (2004) Thinking about the Concept of Teaching Bases on Humanism. Curriculum \& Teaching \& Material, 9, 20-26.

[6] Deng, W. (2009) How to Understand the "Learning Situation”. Basic of Education Research, 14, 56-57.

[7] Gao, Z.L. (2007) Strategies of Knowing Foundation and Needs of Pupils’ Mathematics Learn. Educational Research, 1, 44-46.

[8] Gao, S.Z. (2007) Talking about Learning Situation from The "0 of the Understanding” Teaching. New Curriculum Research (Basic Education), 9, 131-132.

[9] Zhou, Y.L. (2014) Grasping Learning Condition Before Class and Realize the Effective Construction of Learning Condition-Delve The Application of Primary School Mathematics Teachers Understanding Learning Condition Before Class. Chinese Teachers, 1, 73.

[10] Chen, Q. (2015) How to Write “Learning Situation Analysis” Before Lesson. Asia-Pacific Education, 3, 19-20.

[11] Li, W. (2013) Difficulties and Reply Strategies Are Carried out under "Student-Centered”. Chinese Society of Education, 11, 63-66. 